\title{
Spiritual health
}

\author{
A new medico-spiritual health model needs to be recognised
}

Spirituality and healing are two words we encounter more frequently than before, both in the medical and lay press, since the dawn of this century. A leading article in the British Medical Journal (BMJ) addressed spirituality and clinical care and concluded, spiritual values and skills are necessary aspects of clinical care [1]. Another one, also in the $B M J$, discussed the therapeutic effects of meditation and concluded that the evidence is not strong enough [2]. The Lancet published a report showing that spiritual wellbeing and end-of-life despair were inversely related [3]. All these have appeared within last few months. Enthusiasm in the lay press on the subject has equally been high in recent times. Time issued a special supplement on the same topic in January this year [4].

Why this plethora of reports on spirituality and healing? People seem to have recognised limitations of the present mechanistic or biomedical health model. In USA, people now spend more out of pocket on complementary therapies than on orthodox medicine. More and more physical conditions are becoming amenable to psychological interventions. Kabat-Zinn describes how he uses meditation to relieve pain in cancer patients at Massachusetts Hospital's pain clinic [5]. Physical conditions such as infertility, diabetes and viral warts are some conditions now being treated by psychological methods. The effect of mind on skin conditions is well established. A recent review shows how state of mind influences the skin through changes in the level of alpha-melanocyte stimulating hormone in the brain-a centrally acting hormone with anti-inflammatory actions on the skin [6]. Transection of the spinal cord abolishes this response indicating the neural pathway. The effect of mind on eczema can thus be explained. Meditation and recitation of Ave Maria enhance heart rate variability via effects on vagal tone [7]. Enhanced heart rate variability indicates an optimum autonomic balance in the body and is considered to be a sign of good health. Meditation is said to restore the inherent cardiovascular rhythm described by Mayer over a hundred years ago [7]. Effects of mind on the immune system seem to be another mechanism of interaction between body and mind. Depression causes immune suppression. This may be how a woman becomes more vulnerable to cancer after her husband's death.

The description of a functional system-the psychoneuroimmune system (PNI) has facilitated the understanding of how mind can influence the body [8]. This system provides a plausible objective mechanism of body-mind interaction - the link between body and mind [9]. Recognition of this system resulted in Increased interest in body mind research. The Body Mind Institute at Harvard University and the Center for Mindfulness
Medicine at Massachusetts University medical school are only two examples of centres dedicated to body mind research $[10,11]$.

Now there is evidence that people with deep religious commitment have better health and live longer [12]. A systematic review of 23 randomised controlled trials on distant healing practices (spiritual practices) involving 2774 patients showed a positive patient outcome [13]. A single publication offering systematic comprehensive analysis of research on spirituality and healing involving more than 1200 studies and 400 reviews is now available [14]. Here, a 60-80\% relation between better health and religion or spirituality is found in studies covering heart disease, cerebrovascular disease, cancer, etc. As a result, a whole new field of study, epidemiology of religion, has now emerged. A national survey in the USA found that $82 \%$ of Americans believe in spirituality and $64 \%$ felt that their physicians too should pray with them in their need. Another report gives a figure of $76 \%$ as believing in spirituality [15]. The scientific community is now under increasing pressure to undertake research into spiritual health. An interesting parallel is drawn between nutritional deficiency and spiritual deficiency, both of which are believed to retard healing [1].

If spirituality is healing and the evidence is there, why has it not come into the mainstream of medicine? In the mechanistic or biomedical health model we practice today, there is no provision to recognise phenomena based on body-mind interaction. The present health model is based on body-mind dualism proposed by Renê Descartes in 17 th century, assuming that body and mind were two different entities with no interaction [16]. As body-mind interaction can now be explained on the PNI system, we have to accept that the mind can influence healing or has the capacity to heal. Spiritual practices seem to work through enhancing this healing power of the mind.

There is now enough evidence to recognise spirituality as a new dimension in health. However, there is not enough scientific evidence to suggest that spirituality can produce miracles as believed by some people through anecdotal experiences. It is important to emphasise that the healing effects of spirituality, if any, should only be considered as augmenting the effects of accepted scientific medical treatment. It should not be considered as an alternative treatment. Such an approach would be a compromise for both doctors and patients who hold different views on the healing effects of spiritual practices. It will also help reduce patients' overdependence on spirituality which could lead to despair and depression when such practices fail to produce the desired results, and psychotic reactions are a concern at least in some patients practicing spiritual methods for healing [2]. 
Mere recognition of the spiritual dimension is of no use as the present biomedical health model does not allow spirituality to come into the healing process. For this, a new medico-spiritual health model needs to be recognised. Such a model would allow both doctors and patients to recognise and practice spirituality in healing. In Sri Lanka, the trend towards a new health model seems to have already started. Spiritual wellbeing has been identified as part of the vision for a healthier nation in the draft document "Strategy for a healthier nation-2003" released by the Ministry of Health of Sri Lanka in January 2003 [17]. The National Health Research Council of Sri Lanka recently included spiritual health as a research priority [18].

A new medico-spiritual health model would permit health professionals to be trained to address spirituality in health. Hospitals can be given an environment that nourishes patients' inner capacity for healing by providing appropriate spiritual support. Spirituality, as much as physical exercise, should be recognised as health promoting and incorporated in the Ottawa Charter-1986 on health promotion [19]. Adoption of such a medico-spiritual health model in Sri Lanka would show the rest of the world a new direction in health.

\section{References}

1. Culliford L. Spirituality and clinical care. British Medical Journal 2002; 325: 1434-5.

2. Canter PH. The therapeutic effects of meditation. British Medical Journal 2003; 326: 1049-50.

3. McClain C S, Rosenfeld B, William B. Effect of spiritual well-being on end-of-life despair in terminally-ill cancer patients. Lancet 2003; 361: 1603-7.

4. Lemonick M. Your mind, your body. Time (Asia Edition). 2003, January, pp. 35-41.

5. Kabat-Zinn J, ed. Full Catastrophe Living. New York: Dell Publishing, 1990.

6. Lotti T, Bianchi B, Ghersetich I, Brazzini B, Hercogova J. Can the brain inhibit inflammation generated in the skin? The lesson of alpha-melanocyte-stimulating hormone. International Journal of Dermatology 2002; 41: 311-8.
7. Bernardi L, Sleight P, Bandinelli G, Cencetti S, Fattorini $\mathrm{L}$, et al. Effect of rosary prayer and yoga mantras on autonomic cardiovascular rhythms: comparative study. British Medical Journal 2001; 323: 1446-9.

8. Prolo P, Chiapelli F, Fioucci A, Dovio A, Sartori M L, et al. Psychoneuroimmunology: new avenues of research for the twenty-first century. Annals of the New York Academy of Science 2002; 966: 400-8.

9. Bauer SM. Psychoneuroimmunology and cancer: an integrated review. Journal of Advanced Nursing 1994; 19: 1114-20.

10. Benson H, ed. Timeless Healing. New York: Simon \& Scribner Inc. 1996.

11. Center for Mindfulness Medicine. Health Care and Society. http://www.umassmed.edu/cfm/vision/

12. Levin JS. Religion and health: is there an association, is it valid, and is it causal? Social Science and Medicine 1994; 38: $1475-82$.

13. Astin JA, Harkness E, Ernst E. The efficacy of "distant healing": review of randomized trials. Annals of Internal Medicine 2000; 132: 903-10.

14. Koenig HK, Mc Cullough ME, Larson HB. Handbook on Religion and Health. Oxford: Oxford University Press, 2001.

15. Hay D, Hunt K. Understanding the spirituality of people who don't go to church: a report on the findings of the adults' spirituality project. Nottingham: University of Nottingham, 2000.

16. Mayou R, Farmer A. Functional somatic symptoms and syndromes. British Medical Journal 2002; 325: 265.

17. Strategy for a Healthier Nation (Draft document) January 2003. Ministry of Health, Nutrition and Welfare, Democratic Socialist Republic of Sri Lanka.

18. National Health Research Council of Sri Lanka. Council Minutes 2.5. 2003.

19. The move towards new public health-Charter adopted at an international conference on health promotion. Division of Health Promotion, Education and Communication, WHO Geneva. 1986. WHO/HPR/HCP/95-1. Ottawa; 17 21 , November.

S Seneviratne Epa, Consultant physician, Matara Nursing Home, Main Street, Matara, Sri Lanka (Tel: +944122177 , e-mail: mnh@idmmh.ccom.lk). President, Sri Lanka Medical Association, 2003 (Competing interests: none declared). 